\title{
CORRECTION
}

View Article Online

View Journal | View Issue

Check for updates

Cite this: J. Mater. Chem. A, 2021, 9, 26410

DOI: $10.1039 / d 1 t a 90242 c$

rsc.li/materials-a

\section{Correction: The examination of graphene oxide for rechargeable lithium storage as a novel cathode material}

\author{
Da-Wei Wang, ${ }^{\text {ab }}$ Chenghua Sun, ${ }^{c}$ Guangmin Zhou, ${ }^{d}$ Feng Li, ${ }^{d}$ Lei Wen, ${ }^{d}$ \\ Bogdan C. Donose, ${ }^{e}$ Gao Qing (Max) Lu, ${ }^{a}$ Hui-Ming Cheng ${ }^{\star d}$ and lan R. Gentle ${ }^{\star b}$
}

Correction for 'The examination of graphene oxide for rechargeable lithium storage as a novel cathode material' by Da-Wei Wang et al., J. Mater. Chem. A, 2013, 1, 3607-3612, DOI: 10.1039/C3TA01658G.

The authors regret that in the original article the affiliation list was incorrect. The correct affiliations are as shown here; specifically, the order of affiliations $d$ and $e$ has been reversed. This change does not affect the affiliation tags used in the author list, which therefore remain the same.

The Royal Society of Chemistry apologises for these errors and any consequent inconvenience to authors and readers.

${ }^{a}$ Australian Research Council Centre of Excellence for Functional Nanomaterials, Australian Institute for Bioengineering and Nanotechnology, The University of Queensland, Brisbane, QLD 4072, Australia

${ }^{b}$ School of Chemistry and Molecular Biosciences, The University of Queensland, Brisbane, QLD 4072, Australia. E-mail: i.gentle@uq.edu.au

${ }^{c}$ Centre for Computational Molecular Science, Australian Institute for Bioengineering and Nanotechnology, The University of Queensland, Brisbane, QLD 4072, Australia ${ }^{d}$ Shenyang National Laboratory for Materials Science, Institute of Metal Research, Chinese Academy of Sciences, Shenyang, Liaoning 110016, P. R. China. E-mail: cheng@imr.ac. cn

${ }^{e}$ Advanced Water Management Centre, The University of Queensland, Brisbane, QLD 4072, Australia 